\title{
Risk factors for suicide in China's youth: a case-control study
}

\author{
Xianyun $\mathrm{Li}^{1}$, Michael R. Phillips ${ }^{1}$, Yanping Zhang ${ }^{1}$, Dong $\mathrm{Xu}^{1}$, and Gonghuan Yang ${ }^{2}$ \\ ${ }^{1}$ Beijing Suicide Research and Prevention Center, Beijing Hui Long Guan Hospital, Beijing, China \\ ${ }^{2}$ Institute of Basic Medical Sciences, Chinese Academy of Medical Science, Peking Union \\ Medical College, Beijing, China
}

\begin{abstract}
Background-Suicide is the most common cause of death among youth in China.

Method-A case-control psychological autopsy study in 23 geographically representative disease surveillance points around China collected information from family members and close associates of 114 persons 15-24 years of age who died by suicide (cases) and 91 who died of other injuries (controls).
\end{abstract}

\begin{abstract}
Results-Among the 114 suicides $61 \%$ were female, $88 \%$ lived in rural villages, $70 \%$ died by ingesting pesticides (most commonly stored in the home), $24 \%$ previously attempted suicide, and $45 \%$ met criteria of a mental illness at the time of death. Multivariate logistic regression identified several independent risk factors: severe life events within two days before death (OR, 95\%CI; $31.8,2.6-390.6)$, presence of any depressive symptoms within two weeks of death $(21.1,4.6-$ 97.2), low quality of life in the month before death $(9.7,2.8-34.1)$, and acute stress at time of death (moderate: 3.1, 0.8-11.9; high: 9.1, 1.2-66.8). A significant interaction between mental illness at time of death and gender indicated that diagnosis was an important predictor of suicide in males $(14.0,2.6-76.5)$ but not in females $(0.3,0.0-3.6)$. Prior suicide attempt was related to suicide in the univariate analysis $(\mathrm{OR}=57.5)$ but could not be included in the multivariate model because no controls had made prior attempts.
\end{abstract}

Conclusions-Suicide prevention efforts for youth in China must focus on restricting access to pesticides, early recognition and management of depressive symptoms and mental illnesses, improving resiliency, and enhancing quality of life.

\section{INTRODUCTION}

Suicide is one of the leading causes of death among world's youth. In most countries youth suicide rates are much higher in males than females; rates among young males have increased substantially in recent years (Lynskey et al. 2000; Hawton \& James, 2005). Despite the higher rates in males, suicide deaths in persons $15-29$ account for $24.4 \%$ of all male suicides worldwide but $30.5 \%$ of all females suicides (Krug et al. 2002). Mental disorders (especially mood disorders, conduct disorders, substance abuse and disruptive disorders), previous suicide attempts, family history of suicidal behavior, and stressful life events are risk factors for both genders (Gould et al. 1996; Shaffer et al. 1996; Groholt et al. 1997; Groholt et al. 1998; Brent et al. 1999; Beautrais, 2000).

Address for correspondence: Dr. Xianyun Li, Beijing Suicide Research and Prevention Center, Beijing Hui Long Guan Hospital, Beijing 100096, People's Republic of China. Tel: 86-10-8295-1464; Fax: 86-10-8295-1150; xianyunl@ public3.bta.net.cn. 
In China suicide is the leading cause of death among persons 15-24 years of age (Li \& Phillips, 2001a; Phillips et al. 2002a) and the estimated 49,000 annual suicides in this age group account for $17 \%$ of all suicides in the country (Phillips et al. 2002a). The pattern of youth suicides in China is very different from that in the West: female rates are $60 \%$ higher than male rates and rural rates are three-fold urban rates. This study uses data from the national psychological autopsy study to assess the characteristics and risk factors for suicide in this important age group.

\section{METHODS}

\section{Subjects and Sampling}

Most community-based case-control studies of suicide use living controls (Vijaykumar \& Rajkumar, 1999; Mortensen et al. 2000; Beautrais, 2001), but dead controls have methodological advantages (Brent, 1989; Hawton et al. 1998) because the source of information used to assess risk factors - proxy informants who have recently experienced the death of a family member or close associate - is then much more comparable. In China, coroner's reports and medical records are not available so the only information available is that provided by proxy informants, thus it is particularly important to ensure the psychological equivalence of the informants for cases and controls. We chose persons who died of injuries as controls because these deaths, like suicides, are usually sudden and unexpected. Another advantage of injury death controls is that it makes it possible to estimate the proportion of suicide misclassified as injury deaths.

Twenty rural and 3 urban sites were selected from among the 145 sites in the National Disease Surveillance Points (NDSP) network administered by the Chinese Center for Disease Control and Prevention. DSPs with above-average suicide rates identified in each of China's six geographic regions were intentionally selected to be representative of the different economic strata in each region. More rural sites were included because rural population accounts for $65 \%-70 \%$ of the total population in China. In three sites all death certificates coded as suicide, other specific injury, undetermined injury or mental illness for death that occurred from 1 August 1995 to 31 August 2000 were reported to the research group at 3-month intervals. The same procedure was followed in the other 20 sites from 1 January 1998 to 31 August 2000. If more than 5 suicides or 5 specific injury deaths were reported in any 3-month period, 5 cases of each type of death were randomly selected for detailed investigation to ensure that similar numbers of cases and control were identified at each site. If less than 5 decedents of either type were reported, all reported deaths were selected and additional suicides or other injury deaths occurring over the same time period were sequentially selected from adjoining locations if they had a formal death reporting system (many did not). All reported deaths due to mental illness or undetermined injury death were investigated. This continued until 60 deaths were investigated at a site or until the end of recruitment (September 2000).

We defined suicide as a deliberate self-injury resulting in death. Death certificates are typically completed by low-level medical workers (particularly in rural areas) so the accuracy of death certificates was uncertain. Therefore, the final determination of the cause of each death was the consensus opinion of the interviewers and independent researchers after reviewing all available information about the specific events surrounding the death. Misclassified 'injury deaths' and deaths originally attributed to 'mental illness' that were reclassified as suicides by the research team were included in the case group. Thus the final sample of cases is more representative of all suicides.

Overall, 1,932 decedents were selected for psychological autopsy: in 67 cases appropriate informants were not found in 65 identified informants refused to be interviewed and 1 was a 
death from a physical illness. Among the 1,799 decedents chosen for whom a psychological autopsy was completed, 7 died of medical causes, 30 did not have a formal death certificates, 87 were under 10 years of age, and in 22 the interview data were lost. Among the remaining 1,653 decedents, 207 were 15-24 years of age: 110 had a death certificate coded as suicide, 87 as other specific injury, 6 as undetermined injury, and 4 as mental illness. After detailed evaluation, 114 decedents were classified as suicide, 91 as injury death, 1 as non-suicidal self-starvation (in a person with schizophrenia), and 1 as death due to a physical illness (epilepsy) - the latter 2 deaths were not included in the subsequent analyses. The 91 injury death controls included 30 traffic accidents, 16 drownings, 13 murders, 10 electrocutions, 6 accidental falls, 5 crushing injuries, 4 accidental poisonings, 2 deaths from explosions, 2 deaths by fire, 1 death by burial, and 2 unspecified unintentional injuries.

The gender by region (urban or rural) distribution of these 114 suicides is very similar to that estimated for all youth suicides in China for 1995-1999 (Phillips et al. 2002a). Among the suicides identified in this study, urban males, rural males, urban females and rural females accounted for $2.6 \%, 36.8 \%, 6.1 \%$ and $54.4 \%$ of the total sample, respectively. The corresponding proportions in all suicides 15-24 years of age in the country were $3.5 \%$, $34.1 \%, 3.9 \%$ and $58.5 \%$, respectively (Chi square $=0.43, \mathrm{df}=1, \mathrm{P}=0.512$ ). This indicates that the sample is broadly representatives of all youth suicides in China.

Trained researchers, including public-health physicians and psychiatrists, visited each site every 3-6 months and independently administered a comprehensive survey to family members and, separately, to close associates of identified decedents. The survey instrument -which underwent extensive field testing and multiple revisions over a two-year periodhad three main components: 1) an audiotaped open-ended interview about the causes and circumstances of death;2) a structured questionnaire that included information about the circumstances of the death, detailed demographic and socioeconomic status of the deceased, a 60-item life-event scale developed for the study, a quality of life scale, and a medical and psychiatric history; and 3) a semi-structured psychiatric examination based on a slightly revised Chinese version of SCID-P (First et al. 1996) that included all Axis I disorders of the DSM-IV, metal retardation, dementia, and borderline personality; this scale has been used and validated in other studies in China (Li et al. 2001b; Phillips et al. 2002b; Zhang et al. 2004; Shi et al. 2005; Yang et al. 2005).

We obtained informed consent from all proxy informants. The study was approved by the institutional review boards of the Beijing Hui Long Guan Hospital and the Chinese Centers for Disease Control and Prevention. Further details of the methodology are described in previous papers (Phillips et al. 2002b; Phillips \& Yang, 2004; Zhang et al. 2004; Yang et al. 2005).

\section{Measures}

The 'chronic stress score in year prior to death' was the product of the duration (in months) and severity of the psychological effect summed for all negative life events. To quantify the psychological triggering effect of negative life events, an 'acute stress score at time of death' was computed as the product of the severity of the psychological effect and the inverse of the time from the life event to death, summed for all negative life events that continued to has a psychological effect on the deceased up until the time of death. In prior research with attempted suicides we found that the chronic and acute stress scores assessed based on reports of life events by suicide attempters are highly concordant with those based on independent reports by attempter's family members (ICC $=0.72$ and 0.81 , respectively) (Li et al. 2005). 
A depression symptom score reflecting the number, severity, and persistence of depressive symptoms in the two weeks prior to death was derived from the structured psychiatric examination (Phillips et al. 2007). In this analysis this continuous variable was converted to a dichotomous variable: those with and without any symptom of depression (other than suicidal thoughts) for any duration in the two weeks prior to death.

The quality of life of the deceased in the month prior to death was assessed by having respondents rate six characteristics of the deceased (physical health, psychological health, economic circumstances, work, family relationships, and relationships with non-family associates) on a scale of 1 (very poor) to 5 (excellent) and then converting the average sum of the six scores for the two independent respondents to a scale of $0-100$. The internal consistency of the six items in the 402 separate assessments conducted in this study was excellent (alpha $=0.84$ ) and the reliability of the average measure of quality of life of the two informants was also excellent ( $\mathrm{ICC}=0.79$ ).

\section{Statistical Analysis}

Risk factors for youth suicide were identified using unconditional logistic regression where case-control status was regressed on the risk factors. Crude and adjusted odds ratios and their corresponding 95\% confidence intervals were estimated. Given that gender and location of residence are strong determinants of suicides in China, we adjusted the crude odds ratios for these two factors. Risk factors that remained significant after controlling for gender and location of residence were then entered into an overall unconditional logistic regression model. Forward and backward selection procedures were used to identify the final model. The interactions between all significant risk factors with age and sex were tested and the gender by diagnosis interaction was found to be significant, so this interaction term was also included in the final model. Statistical significance in the logistic regression models was assessed using the Wald test statistic. To simplify interpretation of the odds ratios, we categorized several continuous variables into dichotomous variables or tertiles. For each variable coded into tertiles, we assessed its linearity using an orthogonal polynomial contrast. Model performance was assessed by the $\mathrm{C}$-statistic (which is equal to the area under the receiver operating characteristic [ROC] curve) (Hanley et al. 1982) and the Nagelkerke $\mathrm{R}^{2}$ statistic (a measure of the proportion of explained variation in the logistic model) (Nagelkerke, 1991). SPSS-PC software version 11.5 was used for statistical analyses.

There were no reported prior suicide attempts in the control group, so 0.5 was added to all four cells in the 2-by-2 table to estimate an unadjusted odds ratio (Haldane, 1956), but it was not possible to compute an adjusted odds ratio or to include this variable in the multivariate analysis. Previous studies (Brent et al. 1999) have used a hybrid logistic model to deal with this problem (Chen et al. 2003) but in our sample prior suicide attempts in the suicide case group was significantly associated with three other predictors (gender, presence of a mental illness, and severe negative life event in the two days before death) so it was not appropriate to employ this method. Given that prior attempt is strongly associated with suicide in the univariate analysis, non-inclusion of this variable in the multivariate model probably resulted in an inflation in the odds ratios of these three variables.

\section{RESULTS}

There were no significant differences between the 114 suicides and 91 deaths from other injuries by average age [21.3(sd=2.6) vs 20.9(2.6) years], time from death to interview [11.0(5.1) vs 11.0 (4.6) months], and total interview time [213(57) vs 205(64) minutes] (all $\mathrm{p}>0.05)$. There was, however, a significant difference in the average years of education 
[6.0(3.4) vs 7.0(2.7) years, $\mathrm{p}=0.03]$. In the suicide and control groups $4.4 \%$ and $9.9 \%$, respectively, were students.

Of the 114 suicides, $81.6 \%$ died by ingestion of poisons or medications, $12.3 \%$ by hanging, $3.5 \%$ by drowning, $0.9 \%$ by jumping, $0.9 \%$ by traffic accident, and $0.9 \%$ by gunshot. Among the 91 ingestion suicides for whom the agent was known, $63.7 \%$ took agricultural chemicals, $24.2 \%$ rat poisons, $4.4 \%$ medications, and $7.7 \%$ other poisons. In $61.8 \%(55 / 89)$ of the suicides by ingestion the poison or medication was stored, unlocked in the house or yard.

Among the suicides, $10.6 \%$ (12/113) drank alcohol just prior to the suicide; in $16.7 \%$ someone was present observing the suicidal act and in an additional $11.4 \%$ the victim immediately sought assistance after the act; $10.6 \%$ (12/113) wrote a will before the suicide and $19.3 \%$ left a suicide note; $27.4 \%$ (31/113) had discussed death with family members or other associates prior to the suicide; and $57.0 \%$ received medical resuscitation that failed.

The frequency of negative life events among the deceased in the year prior to death was much higher in cases than controls. The most frequent negative life events in the suicide group were loss of face or social embarrassment (43.0\%), economic difficulties (33.3\%), and conflict with parents (32.5\%); while among the 90 control cases with detailed information about life events, the most frequent negative life events were love or engagement problems (27.8\%), economic difficulties (23.3\%) and long-term separation from family $(15.6 \%)$. There were non-significant differences between cases and controls in the rates of being beaten by spouse, beaten by parents, and beaten or raped by others (in female: $13.0 \%$ vs. $0,10.1 \%$ vs. $13.3 \%$, and $7.2 \%$ vs. $0.0 \%$; in males: $0.0 \%$ vs. $0,8.9 \%$ vs. $2.7 \%$, and $4.4 \% v s .2 .7 \%$. Fisher's exact test, all $p>0.05$ ).

Suicide decedents were much more likely to have experienced severe negative life eventstypically intense interpersonal conflicts-in the two days before death: marital disputes (9.6\%), disputes with parents (8.8\%), disputes with other relatives $(5.3 \%)$, being beaten by parents $(4.4 \%)$, intense loss of face or social embarrassment $(4.4 \%)$, being beaten by spouse (2.6\%), and being beaten or raped by others (1.8\%). In the control group, acute severe life events in the two days before death included being frightened $(n=1)$, dissatisfaction with work or study status $(n=1)$, being involved in a physical fight $(n=1)$, conflict with mother inlaw $(n=1)$, and engagement problems $(n=1)$.

Mental disorders were more common among suicides than among those who died of injuries $(44.7 \%$ vs $11.1 \%)$. In the suicide group, the rates of the different psychiatric disorders were as follows: major depressive disorder (28.9\%), schizophrenia (6.1\%), borderline personality disorder $(2.6 \%)$, mental retardation $(1.8 \%)$, alcohol dependence $(0.9 \%)$, substance abuse $(0.9 \%)$, substance dependence $(0.9 \%)$, brief psychotic disorder $(0.9 \%)$, adjustment disorder $(0.9 \%)$, mood disorder due to epilepsy (0.9\%), psychotic disorder due to epilepsy $(0.9 \%)$, and unspecified affective disorder ( $0.9 \%)$. Two of the 114 suicides met criteria for two mental disorders. Depressive symptoms of varying intensity and duration were present in $57.0 \%$ of the suicide decedents, but in many cases these symptoms were not severe enough or did not persist long enough to meet the criteria of a depressive disorder. Only $9.6 \%$ of all suicides and $21.6 \%$ of suicides with a diagnosable mental illness had ever seen a mentalhealth professional and only $7.9 \%$ and $17.6 \%$ had taken psychotropic medications in the month before death. In the 90 controls decedents for whom proxy informants completed the psychiatric examination, the rates of mental disorder were as follows: mental retardation (5.6\%), schizophrenia (2.2\%), alcohol dependence (1.1\%), substance abuse (1.1\%), and substance dependence (1.1\%). 
As shown in Table 1, compared with youth who died of other injuries, youth who died by suicide were more likely to be female and to live in rural villages. After adjusting for gender and location of residence there were no significant differences in the years of formal education, marital status, family financial status, having a pre-school age child or physical health status. The only demographic factors that remained significantly different between cases and controls were employment status (persons engaged in wage-earning jobs and students had lower risk of suicide than agricultural laborers, housewives and the unemployed) and whether or not the individual was functioning in his or her social role up until the time of death.

The suicide and control groups differed significantly on a range of social and psychological factors. Most of these factors remained significantly different after adjustment for gender and location of residence (Table 2). Several risk factors for suicide had a clear dose-response effect: chronic stress score in the past year, increased acute stress at the time of death, and number of chronic negative life events (that lasted longer than one year). Living alone was not a risk factor for suicide. Having a prior suicide attempt was a strong risk factor for suicide but its adjusted OR could not be calculated because there were no prior suicide attempts in the control group. Though significantly more common in cases than in controls, only $44.7 \%$ (51/114) of suicide decedents had a diagnosable mental illness at the time of death; the prevalence of mental illness in female suicide decedents [37.7\% (26/69)] was lower than in male suicide decedents [55.6\% (25/45)] $(\mathrm{Chi}=3.53, \mathrm{df}=1, \mathrm{p}=0.061)$. Among the 63 suicide decedents without a diagnosable illness, 22 (34.9\%) had sub-syndromal depressive symptoms and another 38 had moderate or severe levels of acute stress at the time of death.

Multivariate models identified six independent risk factors for youth suicide: experiencing severe negative life events in the two days before death, the presence of any depressive symptoms in the two weeks before death, low quality of life in the month before death, higher acute stress at the time of death, female gender, and having a mental illness at the time of death (Table 3).

There is a significant interaction between gender and diagnosis (Wald $\mathrm{z}=5.80, \mathrm{p}=0.016$ ) so the Table 3 presents stratified results for these variables. For the gender variable, among those without a diagnosis the risk of suicide is 54.6 times higher in women than men $(\mathrm{p}<0.001)$, but among those with a diagnosis the risk of suicide is not significantly related to gender $(\mathrm{OR}=1.3, \mathrm{p}=0.837)$. Similarly, for the 'met criteria of a psychiatric illness at time of death' variable, among females the risk of suicide is, surprisingly, not significantly associated with diagnostic status ( $\mathrm{OR}=0.3, \mathrm{p}=0.361$ ), but among males the risk of suicide is 14 times higher in those with a diagnosis $(\mathrm{p}=0.002)$. This indicates that females without a mental disorder and males with a mental disorder were at higher risk of suicide, so when counting the number of risk factors to which an individual is exposed gender and diagnostic status are combined into a single risk factor.

Among the 205 suicides and controls, the risk of suicide increases with exposure to an increasing number of risk factors: only $3.0 \%$ (2/67) of those unexposed to any risk factor or only exposed to 1 risk factor died of suicide, while 75.3\% (73/97) exposed to 2 or 3 risk factors died of suicide, and $97.6 \%$ (40/41) exposed to 4 or 5 risk factors died of suicide. The suicide cases were exposed to an average (sd) of $3.16(0.94)$ risk factors versus $0.95(0.94)$ for controls $(\mathrm{t}=16.8, \mathrm{p}<0.001)$; the average for females was $2.81(1.00)$ versus 1.74 (1.52) for males $(\mathrm{t}=5.6, \mathrm{p}<0.001)$. 


\section{DISCUSSION}

With the exception of a lower rate of diagnosable mental illness ( $45 \%$ vs $66 \%$ ), the characteristics of youth suicides found in this study are similar to those of suicide victims in other age groups in China (Phillips et al. 2002b). Characteristics of Chinese youth suicides are, however, different from those reported in Western countries where pesticide ingestion is uncommon, most suicides are male, over $90 \%$ have a mental illness, and many have multiple mental illnesses (Gould et al. 1996; Shaffer et al. 1996; Dudley et al. 1998; Brent et al. 1999; Beautrais 2000; Maris et al. 2000; Agerbo et al. 2002; Gould et al. 2003).

In Western studies a history of physical or sexual abuse is strongly associated with suicidal behavior (Coll et al. 2001; Edgardh et al. 2000; Evans et al. 2005; Martin et al. 2004;

Molnar et al. 2001). Consistent with Western studies, in the current study informant reports of prior physical or sexual abuse among female decedents was more common in those died of suicide than of injuries, but the difference was not statistically significant.

The low social status of women in rural China contributes to their relatively high rates of completed suicide, but we believe that the ready availability of toxic pesticides is a more important factor (Phillips et al. 2002b). In rural China most households own a small plot of farmland and try to increase crop yields by using cheap but highly lethal pesticides, which are usually stored in the house or yard. The frequent use of pesticide ingestion among those who engage in suicidal behavior, the higher rate of suicidal behavior in young females compared to young males (about 2.5 to 1), and the lack of the technical competence and equipment required to effectively manage pesticide ingestion in rural areas may lead to an increased fatality among persons who engage in low-intent suicidal acts and, thus, a relative increase in the numbers of young females who die by suicide (Phillips et al. 2002b; Conner et al. 2005; Conner et al. in press).

Despite different characteristics, the pattern of risk factors in youth suicides is quite similar in China and the West. In Western countries prior suicide attempt, mental illness, family history of suicidal behavior and mental disorders, experiencing stressful life events, and the ready availability of firearms are key risk factors (Gould et al. 1996; Beautrais 2000; Maris et al. 2000; Agerbo et al. 2002; Gould et al. 2003). In China, these are also key risk factors (with the role of firearms replaced by pesticides); but the importance of recent severe negative life events, depressive symptoms, and low quality of life in the month before death appear to be greater than in the West.

The much lower prevalence and low comorbidity of mental disorders compared to that reported for youth suicides in Western countries (Breautrais 2000; Brent et al. 1999) suggests that mental disorders play a less central—-though still important—role in youth suicide in China. This lower prevalence and comorbidity is partially explained by the much lower rates of substance abuse in China: only 3 of the 114 (2.6\%) suicide decedents in our study met diagnostic criteria for substance abuse or dependence. These low rates of mental disorders are not unprecedented: several studies of youth suicide in the West find that for younger adolescents (age less than 16) the rates of psychiatric disorder can be in the $40 \%$ to 60\% range (Shaffer et al. 1996; Groholt et al. 1997; Brent et al. 1999). One possibility is that the absence of substance abuse problems extends the early adolescent pattern of suicide into later ages in China.

In our study mental illness was an important predictor of suicide in males but $N O T$ in females. This surprising finding is at odds with published studies from the west but is supported by other studies of fatal and non-fatal suicidal behavior in China (Conner et al. 2005; Conner et al. in press; Li et al. 2003; Li et al. 2005; Yang et al. 2005) which find that 
impulsive, low-intent suicidal behavior involving the ingestion of lethal pesticides is common among young Chinese females.

The absence of a diagnosable mental illness in suicide decedents does not mean that they are not distressed. Ninety-five percent of them either had sub-syndromal depressive symptoms or acute stress (typically related to a precipitating interpersonal conflict) at the time of death. Among all decedents, experiencing a severe life event in the two days before death and having any depressive symptoms for any duration in the two weeks prior to death were more important predictors youth suicide than depression. Therefore, the focus of preventing youth suicide in China should be on increasing resilience to acute psychosocial stressors and the timely recognition and management of depressive symptoms - even sub-syndromal depressive symptoms (Phillips et al.2007).

The low rate of care-seeking in suicide decedents with a mental illness (21.6\%) highlights the need for innovative programs aimed at changing attitudes about care-seeking for psychological problems among youth. Improving the recognition and management of subsyndromal depressive symptoms will also require increased public educational efforts among youth and those who interact with youth (parents, teachers, general physicians, etc.) about the characteristics and treatment of depressive symptoms.

Strategies aimed at enhancing the resilience of youth-especially those who have had prior suicide attempts, who are experiencing acute stress, or who have a poor quality of life - are also important components of a comprehensive suicide prevention effort for youth. Such strategies might include public health education about suicide, enhancing the social support system for rural women, peer-support programs for students, and problem-solving skill training (Speckens \& Hawton, 2005; McAuliffe et al. 2005). Given that $70 \%$ of youth suicides in China involved ingestion of pesticides or rat poisons, suicide prevention efforts also need to promote safe and secure home storage of poisons.

\section{Limitations}

In addition to the limitations of the psychological autopsy method (Hawton et al. 1998), this study had other limitations that should be considered when interpreting the results.

A control group of deceased individuals has the advantage of ensuring similarity among the informants, but the disadvantage that young persons who die of injuries tend to be male 'risk-takers'. We tried to minimize this problem by adjusting all risk factor estimates for gender, but the controls may differ from the general population in other ways (, e.g., higher rates of substance abuse). In this situation one can be reasonably certain about the identified risk factors but there may be additional risk factors that would have emerged if a living control group were employed.

Despite being one of the largest studies on adolescent suicide reported, the sample was still somewhat small for developing a stable multivariate model of risk factors. Some significant but uncommon risk factors may have dropped out from the final model and the precision of some of the estimated odds ratios is poor. The extreme example of this was the absence of any prior suicide attempts in the control group which made it impossible to include this important risk factor in the multivariate analysis. The relatively long interval between the death and the interviews of informants (median time of 11.0 months), a practical necessity given the size of the study and the death reporting practices of the participating sites, could have resulted in under-reporting of mental illnesses and other recall-bias related problems. But the interval between cases and controls was not statistically different so the estimates of odds ratios are unlikely to be biased. Moreover, a previous report found no differences over time in the number and type of symptoms reported by proxy informants, so recall bias does 
not appear to change over time following a death by suicide or injury (Phillips et al. 2002b). Supporting evidence for the reported low rate of diagnosable mental illness in fatal suicides also comes from studies of serious suicide attempters in China who are interviewed immediately after the attempt and in whom rates of diagnosable mental illness are about $40 \%$ (Li et al. 2005). The 5-year duration of the data collection period could have affected the results, but the gender by age by region (urban versus rural) pattern of suicides nationally did not change over the time period of the study (Phillips et al. 2002a) so it is unlikely that there were substantial changes in the risk factors for youth suicide over the period.

These issues aside, the key findings of this paper identify for the first time risk factors and characteristics for youth suicide in China and show that there are many similarities but also important differences with those found for Western youth: 1) most youth die by ingestion of pesticides; 2) fatal suicidal behavior is more prevalent in women than men, possibly due to the frequent use of lethal pesticides in low-intent suicidal acts by young women in rural areas; 3 ) acute negative life events and sub-syndromal depressive symptoms are more important risk factors than diagnosable mental illness, particularly among women; and 4) substance abuse or dependence is uncommon. These findings imply that youth suicide prevention efforts in China should focus on restricting access to pesticides, on enhancing psychological resilience, and on identifying and treating symptoms of depression.

\section{Acknowledgments}

This study is part of the "Causes and Prevention of Accidental Deaths in China" project, which was supported by grants from the Ford Foundation, the Save the Children Fund, and Befrienders International. Participating institutions include 23 Disease Surveillance Points and four psychiatric centers (Department of Neuropsychiatry, Xijing Hospital, Xian, Shaanxi Province; Jingzhou City Psychiatric Hospital, Hubei Province; Shenyang Mental Health Center, Liaoning Province; and Suzhou Guangji Hospital, Jiangsu Province). The authors thank all the institutions, investigators and respondents for their contribution to the research. We also thank Annette Beautrais and Mark Davies for their comments on the manuscript and Alex Cohen's contribution on the revision. While preparing this manuscript the first author was partly supported by the NIH Fogarty International Center grants 5 D43 TW007273 to E. Caine and 5 D43 TW05809 to B.J. Good.

\section{REFERENCES}

Agerbo E, Nordentoft M, Mortensen PB. Familial, psychiatric, and socioeconomic risk factors for suicide in young people: nested case-control study. British Medical Journal. 2002; 325:74-78. [PubMed: 12114236]

Beautrais AL. Risk factors for suicide and attempted suicide among young people. Australian and New Zealand Journal of Psychiatry. 2000; 34:420-436. [PubMed: 10881966]

Beautrais AL. Suicides and serious suicide attempts: two populations or one? Psychological Medicine. 2001; 31:837-845. [PubMed: 11459381]

Brent DA. The psychological autopsy: methodological considerations for the study of adolescent suicide. Suicide and Life-Threatening Behavior. 1989; 19:43-57. [PubMed: 2652387]

Brent DA, Baugher M, Bridge J, Chen T, Chiappetta L. Age- and sex-related risk factors for adolescent suicide. Journal of the American Academy of Child and Adolescent Psychiatry. 1999; 38:1497-1505. [PubMed: 10596249]

Chen TH, Hoppe FM, Iyengar S, Brent D. A hybrid logistic model for case-control studies. Methodology and Computing in Applied Probability. 2003; 5:419-426.

Coll X, Law F, Tobias A, Hawton K, Tomas J. Abuse and deliberate self-poisoning in women: a matched case-control study. Child Abuse \& Neglect. 2001; 25:1291-1302. [PubMed: 11720380]

Conner KR, Phillips MR, Meldrum S. Variability in Intention to Die in Suicide Attempts in China. American Journal of Public Heatlh. (in press).

Conner KR, Phillips MR, Meldrum S, Knox KL, Zhang YP, Yang GH. Low-planned suicides in China. Psychological Medicine. 2005; 35:1197-1204. [PubMed: 16116945] 
Dudley MJ, Kelk NJ, Florio TM, Howard JP, Waters BG. Suicide among young Australians, 19641993: an interstate comparison of metropolitan and rural trends. Medical Journal of Australia. 1998; 169:77-80. [PubMed: 9700341]

Edgardh K, Ormstad K. Prevalence and characteristics of sexual abuse in a national sample of Swedish seventeen-year-old boys and girls. Acta paediatrica. 2000; 88:310-319. [PubMed: 10772279]

Evans E, Hawton K, Rodham K. Suicidal phenomena and abuse in adolescents: a review of epidemiological studies. Child Abuse \& Neglect. 2005; 29:45-58. [PubMed: 15664425]

First, MB.; Spitzer, RL.; Gibbon, M.; Williams, JBW. Structured Clinical Interview for DSM-IV Axis I Disorders-Patient Edition (SCID-I/P, Version 2.0, 8/98revision). New York: Biometrics Research Department; 1996.

Gould MS, Fisher P, Parides M, Flory M, Shaffer D. Psychosocial risk factors of child and adolescent completed suicide. Archives of General Psychiatry. 1996; 53:1155-1162. [PubMed: 8956682]

Gould MS, Greenberg T, Velting DM, Shaffer D. Youth suicide risk and preventive interventions: a review of the past 10 years. Journal of the American Academy of Child and Adolescent Psychiatry. 2003; 42:386-405. [PubMed: 12649626]

Groholt B, Ekeberg O, Wichstrom L, Haldorsen T. Suicide among children and younger and older adolescents in Norway: a comparative study. Journal of the American Academy of Child and Adolescent Psychiatry. 1998; 37:473-481. [PubMed: 9585647]

Groholt B, Ekeberg O, Wichstrom L, Haldorsen T. Youth suicide in Norway, 1990-1992: a comparison between children and adolescents completing suicide and age- and gender-matched controls. Suicide and Life-Threatening Behavior. 1997; 27:250-263. [PubMed: 9357080]

Haldane JBS. The estimation and significance of the logarithm of a ratio of frequencies. Annals of Human Genetics. 1956; 20:309-311. [PubMed: 13314400]

Hanley JA, McNeil BJ. The meaning and use of the area under the receiver operating characteristic (ROC) curve. Radiology. 1982; 143:29-36. [PubMed: 7063747]

Hawton K, James A. Suicide and deliberate self harm in young people. British Medical Journal. 2005; 330:891-894. [PubMed: 15831877]

Hawton K, Appleby L, Platt S, Foster T, Cooper J, Malmberg A, Simkin S. The psychological autopsy approach to studying suicide: a review of methodological issues. Journal of Affective Disorders. 1998; 50:269-276. [PubMed: 9858086]

Krug, EG.; Dahlberg, LL.; Mercy, JA.; Zwi, AB.; Lozano, R., editors. World Report on Violence and Health. Geneva: World Health Organization; 2002.

Li XY, Phillips MR. The importance of suicide among reproductive age groups in China in 1998. Chinese Public Health Journal. 2001a; 17:658-670. (in Chinese).

Li XY, Phillips MR, Ji HY, Xu YC, Bian QT, He FS. The characteristics of serious suicide attempters living in villages. Chinese Journal of Nervous and Mental Disorders. 2005; 31:272-277. (in Chinese).

Li XY, Phillips MR, Wang YP, Zhang C, Ji HY, Bian QT, Ma ZW, He FS. Comparison of impulsive and non-impulsive attempted suicide. Chinese Journal of Nervous and Mental Disorder. 2003; 29:27-31. (in Chinese).

Li XY, Yang RS, Zhang C, Bian QT, Ji HY, Wang YP, Zheng YX, He FS, Phillips MR. A casecontrol study of the risk factors in attempted suicide. Chinese Journal of Epidemiology. 2001b; 22:281-283. (in Chinese). [PubMed: 11718067]

Lynskey M, Degenhardt L, Hall W. Cohort trends in youth suicide in Australia 1964-1997. Australian and New Zealand Journal of Psychiatry. 2000; 34:408-412. [PubMed: 10881964]

Maris, RW.; Berman, AL.; Silverman, MM.; Nisbet, PA. Age and the lifespan. In: Maris, RW.; Berman, AL.; Silverman, MM., editors. Comprehensive textbook of suicidology. New York: The Guilford Press; 2000. p. 127-145.

Martin G, Bergen HA, Richardson AS, Roeger L, Allison S. Sexual abuse and suicidality: gender differences in a large community sample of adolescents. Child Abuse \& Neglect. 2004; 28:491503. [PubMed: 15159067]

McAuliffe C, Corcoran P, Keeley H, Arensman E, Bille-Brahe U, De Leo D, Fekete S, Hawton K, Hjelmeland H, Kelleher M, Kerkhof AJFM, Lonnqvist J, Michel K, Salander-Renberg EL, 
Schmidtke A, van Heeringen K, Wasserman D. Problem-solving ability and repetition of deliberate self-harm: a multicentre study. Psychological Medicine. 2005; 35:1-11.

Molnar BE, Berkman LF, Buka SL. Psychopathology, childhood sexual abuse and other childhood adversities: relative links to subsequent suicidal behaviour in the US. Psychological Medicine. 2001; 31:965-977. [PubMed: 11513382]

Mortensen PB, Agerbo EE, Qin T, Westergaard-Nielsen N. Psychiatric illness and risk factors for suicide in Denmark. The Lancet. 2000; 355:9-12.

Nagelkerke NJD. A note on general definition of the coefficient or determination. Biometrika. 1991; 78:691-692.

Phillips MR, Li XY, Zhang YP. Suicide rates in China, 1995-99. The Lancet. 2002a; 359:835-840.

Phillips MR, Shen QJ, Liu XH, Pritzker S, Streiner D, Conner K, Yang GH. Assessing depressive symptoms in persons who die of suicide in mainland China. Journal of Affective Disorders. 2007; 98:73-82. [PubMed: 16945424]

Phillips MR, Yang GH. Suicide and attempted suicide in China, 1990-2002. Morbidity and Mortality Weekly Report. 2004; 53:481-484. [PubMed: 15190245]

Phillips MR, Yang GH, Zhang YP, Wang LJ, Ji HY, Zhou MG. Risk factors for suicide in China: a national case-control psychological autopsy study. The Lancet. 2002b; 360:1728-1736.

Shaffer D, Gould MS, Fisher P, Trautman P, Moreau D, Kleinman M, Flory M. Psychiatric diagnosis in child and adolescent suicide. Archives of General Psychiatry. 1996; 53:339-348. [PubMed: 8634012]

Shi QC, Zhang JM, Xu FZ, Phillips MR, Xu Y, Fu YL, Gu W, Zhou XJ, Wang SM, Zhang Y, Yu M. Epidemiological survey of mental illnesses in the people aged 15 and older in Zhejiang Province. Chinese Journal of Preventive Medicine. 2005; 39:229-236. (in Chinese). [PubMed: 16194375]

Speckens AEM, Hawton K. Social problem solving in adolescents with suicidal behavior: a systematic review. Suicide and Life-Threatening Behavior. 2005; 35:365-387. [PubMed: 16178693]

Vijaykumar L, Rajkumar S. Are risk factors for suicide universal? A case control study in India. Acta Psychiatrica Scandinavica. 1999; 99:407-411. [PubMed: 10408261]

Yang GH, Phillips MR, Zhou MG, Wang LJ, Zhang YP, Xu D. Understanding the unique characteristics of suicide in China: national psychological autopsy study. Biomedical and Environmental Sciences. 2005; 18:379-389. [PubMed: 16544520]

Zhang YP, Li XY, Wang LJ, Zhao YX, Meng M, Zhang FG, Peng J, Shen MH, Liu YC, Jiao ZK, Yang GH, Phillips MR. National case-control study of suicide and accidental death. Chinese Mental Health Journal. 2004; 18:861-864. (in Chinese). 


\section{Table 1}

Comparison of demographic characteristics of suicides and deaths from other injuries in persons 15-24 years of age in China

\begin{tabular}{|c|c|c|c|c|}
\hline Variables & $\begin{array}{c}\text { Suicide } \\
(\mathrm{N}=114)\end{array}$ & $\begin{array}{l}\text { Death from } \\
\text { other injuries } \\
\quad(\mathrm{N}=91)\end{array}$ & $\begin{array}{c}\text { Crude } \\
\text { Odds Ratio } \\
\text { (95\% CI ) }\end{array}$ & $\begin{array}{c}\text { Adjusted Odds } \\
\text { Ratio* } \\
\text { (95\% CI ) }\end{array}$ \\
\hline Female & $69(60.5 \%)$ & $15(16.5 \%)$ & $7.8(4.0-15.2)$ & .. \\
\hline Lived in villages & $100(87.7 \%)$ & $65(71.4 \%)$ & $2.9(1.4-5.9)$ & .. \\
\hline \multicolumn{5}{|l|}{ Years of formal education } \\
\hline$\geq 7$ years & $45(39.5 \%)$ & $51(56.0 \%)$ & 1.0 & 1.0 \\
\hline $1-6$ years & $57(50.0 \%)$ & $37(40.7 \%)$ & $1.7(0.98-2.4)$ & $1.3(0.6-2.4)$ \\
\hline None & $12(10.5 \%)$ & $3(3.3 \%)$ & $4.5(1.2-17.1)$ & $2.6(0.6-4.1)$ \\
\hline \multicolumn{5}{|l|}{ Monthly per capita income in family } \\
\hline$\leq 120$ Yuan $^{* *}$ & $42(36.8 \%)$ & $28(30.8 \%)$ & 1.0 & 1.0 \\
\hline $121-250$ Yuan $^{* *}$ & $39(34.2 \%)$ & $30(33.0 \%)$ & $0.9(0.4-1.7)$ & $0.9(0.4-1.9)$ \\
\hline$\geq 251$ Yuan $^{* *}$ & $33(28.9 \%)$ & $33(36.3 \%)$ & $0.7(0.3-1.3)$ & $1.1(0.5-2.5)$ \\
\hline Currently married & $41(36.0 \%)$ & $19(20.9 \%)$ & $2.1(1.1-4.0)$ & $1.1(0.5-2.3)$ \\
\hline \multicolumn{5}{|l|}{ Employment status } \\
\hline Wage-earning job or student & $35(30.7 \%)$ & $54(59.3 \%)$ & 1.0 & 1.0 \\
\hline Agricultural laborer & $63(54.4 \%)$ & $31(34.1 \%)$ & $3.1(1.7-5.7)$ & $2.8(14-5.9)$ \\
\hline Unemployed or housewives & $17(14.9 \%)$ & $6(6.6 \%)$ & $4.4(1.6-12.2)$ & $3.9(1.2-12.7)$ \\
\hline Had a physical disability & $7(6.1 \%)$ & $1(1.1 \%)$ & $5.8(0.7-48.2)$ & $6.5(0.7-57.9)$ \\
\hline Functioned in social role up until time of death & $90(78.9 \%)$ & $84(92.3 \%)$ & $0.3(0.1-0.8)$ & $0.2(0.1-0.7)$ \\
\hline Had pre-school age child in home & $26(22.8 \%)$ & $10(11.0 \%)$ & $2.4(1.1-5.3)$ & $1.0(0.4-2.6)$ \\
\hline
\end{tabular}

Because of rounding, not all percentages total 100 .

* Adjusted for sex and location of residence (villages vs cities/suburbs/towns).

$* *$

At the time of the study 8.26 Yuan=US\$ 1. 
Table 2

Comparison of psychological, social environment, and life event characteristics of suicides and deaths from other injuries in persons 15-24 years of age in China

\begin{tabular}{|c|c|c|c|c|}
\hline Variables & $\begin{array}{l}\text { Suicide } \\
(\mathrm{N}=114)\end{array}$ & $\begin{array}{c}\text { Death from } \\
\text { other injuries } \\
\text { ( N=91 ) }\end{array}$ & $\begin{array}{c}\text { Crude } \\
\text { Odds Ratio } \\
\text { ( } 95 \% \text { CI ) }\end{array}$ & $\begin{array}{c}\text { Adjusted Odds } \\
\text { Ratio* } \\
\text { ( 95\% CI ) }\end{array}$ \\
\hline \multicolumn{5}{|l|}{ Psychological factors } \\
\hline \multicolumn{5}{|l|}{ Chronic stress score in year before death ${ }^{* *}$} \\
\hline Lowest tertile $(<12)$ & $20(17.5 \%)$ & $48(53.3 \%)$ & 1.0 & 1.0 \\
\hline Middle tertile (12-47) & $40(35.1 \%)$ & $28(31.1 \%)$ & $3.4(1.7-7.0)$ & $4.1(1.8-9.4)$ \\
\hline Highest tertile $(\geq 48)$ & $54(47.4 \%)$ & $14(15.6 \%)$ & $9.3(4.2-20.3)$ & $11.9(4.8-29.9)$ \\
\hline \multicolumn{5}{|l|}{ Acute stress score at time of death ${ }^{* *}$} \\
\hline Lowest tertile & $12(10.5 \%)$ & $58(64.4 \%)$ & 1.0 & 1.0 \\
\hline Middle tertile & $42(36.8 \%)$ & $24(26.7 \%)$ & $8.5(3.8-18.8)$ & $8.6(3.5-21.1)$ \\
\hline Highest tertile & $60(52.6 \%)$ & $8(8.9 \%)$ & $36.3(13.8-95.1)$ & $37.0(12.4-110.2)$ \\
\hline Had any depressive symptoms in two weeks before death & $65(57.0 \%)$ & $6(6.6 \%)$ & $18.8(7.6-46.6)$ & $23.6(8.7-64.3)$ \\
\hline Met criteria of a psychiatric illness at time of death & $51(44.7 \%)$ & $10(11.1 \%)$ & $6.5(3.0-13.8)$ & $9.1(3.9-21.6)$ \\
\hline Had ever sought help for a psychological problem & $18(15.8 \%)$ & $2(2.2 \%)$ & $8.3(1.9-37.0)$ & 7.8(1.7-36.2) \\
\hline Used psychotropic medication in the month before death & $9(7.9 \%)$ & $1(1.1 \%)$ & 7.7(1.0-62.1) & $5.3(0.6-46.4)$ \\
\hline \multicolumn{5}{|l|}{ Social environment } \\
\hline Had made previous suicide attempt & $27(23.7 \%)$ & 0 & $57.5(3.5-957.8)^{* * *}$ & ------ \\
\hline Had blood relative with suicidal behavior & $17(15.2 \%)$ & $4(4.5 \%)$ & $3.8(1.2-11.6)$ & $3.6(1.1-12.2)$ \\
\hline Friends or associates had suicidal behavior & $37(33.0 \%)$ & $11(12.6 \%)$ & $3.4(1.6-7.2)$ & $3.9(1.7-8.8)$ \\
\hline Low quality of life score in month before death $(<66$, range $0-100)$ & $82(71.9 \%)$ & $22(24.4 \%)$ & $7.9(4.2-14.9)$ & $10.7(5.0-23.2)$ \\
\hline Decreased level of social activities in month before death & $16(14.0 \%)$ & $4(4.4 \%)$ & $3.6(1.1-11.0)$ & $2.9(0.8-10.1)$ \\
\hline Lived alone & $9(7.9 \%)$ & $11(12.1 \%)$ & $0.6(0.2-1.6)$ & $0.9(0.3-2.5)$ \\
\hline $\begin{array}{l}\text { Deceased's physical illness (if any) had negative effect on family } \\
\text { members }\end{array}$ & $15(13.2 \%)$ & $2(2.2 \%)$ & $6.7(1.5-30.0)$ & $7.7(1.6-36.4)$ \\
\hline \multicolumn{5}{|l|}{ Life events } \\
\hline \multicolumn{5}{|l|}{ Number of chronic negative life events (lasting $\geq 1$ year) ${ }^{* *}$} \\
\hline 0 & $31(27.2 \%)$ & $44(48.9 \%)$ & 1.0 & 1.0 \\
\hline $1-2$ & $42(36.8 \%)$ & $33(36.7 \%)$ & $1.8(0.9-3.5)$ & $2.0(1.0-4.3)$ \\
\hline$\geq 3$ & $41(36.0 \%)$ & $13(14.4 \%)$ & $4.5(2.1-9.7)$ & $5.3(2.2-13.0)$ \\
\hline Experienced severe life event in the two days before death & $43(37.7 \%)$ & $5(5.6 \%)$ & $10.3(3.9-27.4)$ & $11.4(3.9-33.1)$ \\
\hline
\end{tabular}


Table 3

Multivariate model of risk factors for 15-24-year-old youth suicide in China comparing 114 suicides and 90 deaths from other injuries*

\begin{tabular}{|c|c|}
\hline Variables & Adjusted odds ratio $(95 \% \mathrm{CI})$ \\
\hline Lived in villages (vs. cities, suburbs or towns) & $3.4(0.9-12.3)$ \\
\hline Experienced severe life event in the two days before death & $31.8(2.6-390.6)$ \\
\hline Had any depressive symptoms in two weeks prior to death & $21.1(4.6-97.2)$ \\
\hline Low quality of life score in month before death $(<66$,range $0-100)$ & $9.7(2.8-34.1)$ \\
\hline \multicolumn{2}{|l|}{ Acute stress score at time of death ${ }^{* *}$} \\
\hline Lowest tertile & 1.0 \\
\hline Middle tertile & $3.1(0.8-11.9)$ \\
\hline Highest tertile & $9.1(1.2-66.8)$ \\
\hline \multicolumn{2}{|l|}{ Gender $^{* * *}$ (female vs male) } \\
\hline Did not meet criteria of a psychiatric illness at time of death & $54.6(9.5-315.6)$ \\
\hline Met criteria of a psychiatric illness at time of death & $1.3(0.1-12.8)$ \\
\hline Met criteria of a psychiatric illness at time of death & $4.7(1.2-18.6)$ \\
\hline Female & $0.3(0.0-3.6)$ \\
\hline Male & $14.0(2.6-76.5)$ \\
\hline \multicolumn{2}{|c|}{$\begin{array}{l}* \\
\text { Prior suicide attempt was not considered in the multivariate model because none of the control decedents had prior attempts. Nagelkerke } \mathrm{R}^{2} \text { for } \\
\text { the model is } 0.806 \text { and the } \mathrm{C} \text { statistic is } 0.966 .\end{array}$} \\
\hline \multicolumn{2}{|c|}{$\begin{array}{l}\text { T** } \\
\text { There is a significant interaction between gender and diagnosis (Wald } \mathrm{z}=5.80, \mathrm{p}=0.016) \text {, so the table presents stratified results. For the gender } \\
\text { variable, among those without a diagnosis the risk of suicide is } 54.6 \text { times higher in women than men }(\mathrm{p}<0.001) \text {, but among those with a diagnosis } \\
\text { the risk of suicide is not significantly related to gender }(\mathrm{OR}=1.3, \mathrm{p}=0.837) \text {. Similarly, for the 'met criteria of a psychiatric illness at time of death' } \\
\text { variable, among females the risk of suicide is, surprisingly, not significantly associated with diagnostic status }(\mathrm{OR}=0.3 \text {, } \mathrm{p}=0.361) \text {, but among males } \\
\text { the risk of suicide is } 14 \text { times higher in those with a diagnosis }(\mathrm{p}=0.002) \text {. }\end{array}$} \\
\hline
\end{tabular}

